\title{
COMPENSATION OF DEFECTS IN PRINTING PROCESS WITH HISTOGRAM METHODS
}

\author{
Ekaterina Pukhova (D), Vladislav Vereshchagin \\ Moscow Polytechnic University, Faculty of Information Technology, Moscow, Russia
}

\begin{abstract}
A method of image preparation for printing reproduction is suggested. This method allows to automatically compensate transformations that occur during reproduction, by analyzing a histogram of test chart image and based on it, creating a compensation pre-correction function. It also takes into consideration the visual perception of images. Pre-correction function is applied to images at the prepress stage after all other corrections. It is aimed to compensate defects, occurring at the printing stage, caused by the process of tone value increase and restriction of tonal range reproduction. It is suggested to use a test chart, which is a gradient with an even increase of lightness in the range from 0 to 255. After printing the test chart its digital image is created by scanning. Then Gaussian filter is applied to the image with parameters according to the visual perception, and lightness distribution histogram is calculated. This histogram will have changes in lightness distribution in comparison with the original digital image. These changes will correspond to the influence of tone value increasing process during printing. The cumulative sum is calculated from the received histogram, and the pre-correction is being formed. And this precorrection applies to an image, prepared for printing in similar conditions as test chart. The algorithm was written on Python and allows to create a pre-correction using a press sheet with the test chart. It is shown that the use of the suggested method gives a positive result and doesn't require expensive measurement equipment. Having a scanner calibrated for linear transmission of lightness and developed programming module is enough. This method was tested on electrographic printing equipment on three different types of paper. Statistic parameters of a histogram, such as mean, standard deviation and the Skewness, were used for evaluation. It is shown that the suggested method can be used as part of an automatized system based on histogram methods for image preparation before printing.
\end{abstract}

Keywords: tone value increase, histogram methods, pre-correction functions

\section{INTRODUCTION}

There are two main stages during the process of image reproduction: digital and printing. On the digital stage color and tone value correction, sharpness increase and compensation of defects, typical for the printing stage, using color management system is made (Hunt, 2004; Gonzalez \& Woods, 2018). Color management is the most automatized stage of whole process, but requires a huge amount of measurements, using a spectrophotometer and specialized software (Маргулис, Д, 2003).

On each stage of reproduction process image histogram changes (Пухова et al, 2018). This changes correlate with the degree and nature of the influence on the image. This correlation allows to use the image histogram as the main tool for controlling processes of correction and reproduction.

There is a suggested effective method of automatic correction of monochrome and colored images, using the law of normal distribution for histogram specification (Пухова and Андреев, 2017; Пухова and Андреев, 2014; Пухова and Андреев, 2018). This correction method removes gradation distortions, raises contrast and allows to reach psychological accuracy of tone perception in the image, intended for representation (Пухова and Андреев, 2017).

Digital imprint image histogram represents changes, depending on halftoning method, printing process and visual perception (Нюберг, Н.Д., 1947; Пухова et al, 2018). It means that a histogram contains information about main distortions, occurring during the printing process. There is an aim to develop algorithm that allows to consider printing distortions, during preparation for the printing stage, based on the analysis of the digital imprint image histogram. It creates a possibility to develop the unified automatized system of image preparation, minimizing costs for measuring equipment and simplifying of process.

\section{METHODS}

We will base on the fact that used materials and tone increasing process affect on the range of tone reproduction and distribution of tones inside the range (Пухова et al, 2016). Therefore, it is necessary to evaluate changes in the histogram during the printing process and calculate pre-correction function, using 
this information. This function is had to be applied to the image before printing. It is suggested to use histogram methods to solve the problem.

If there is the image histogram his $(I)=n_{i} / N$, where $I$ is the tone level, $n_{i}-$ number of pixels, corresponding to the level I, $\mathrm{N}$ is the number of pixels in the image, it is possible to count cumulative sum - cs (1).

$c s=\sum_{l=0}^{k} h i s(l) \quad k=0,1, \ldots, L-1$

There is the known method that allows to give base image histogram a shape of distribution close to the sample. In this case firstly cumulative sum is counted, then transformation function $T(I)=\operatorname{cs} \times 255$ is calculated and inverse function is applied to the equalized histogram of corrected image (Gonzalez and Woods, 2018).

$\operatorname{Tk}(I)=T^{-1}(I)$

This method showed itself well in correction of images from different sources and in bringing them to the unified view, when reproducing in one issue (Пухова and Андреев, 2018). It is suggested to develop the algorithm of pre-correction compensation of defects in printing process, based on this method.

It is necessary to evaluate the influence of printing process on tonal distribution in all range, for solving the problem of calculating pre-correction function, considering distortions of the printing process. Any changes in tone transmission during the printing process will change the shape of the histogram, therefore changes in the shape of the histogram will represent distortions of the printing process. The test image with equal distribution of tones in the range from 0 to 255 is used (Figure 1).

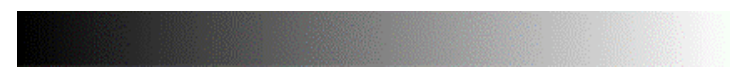

a)

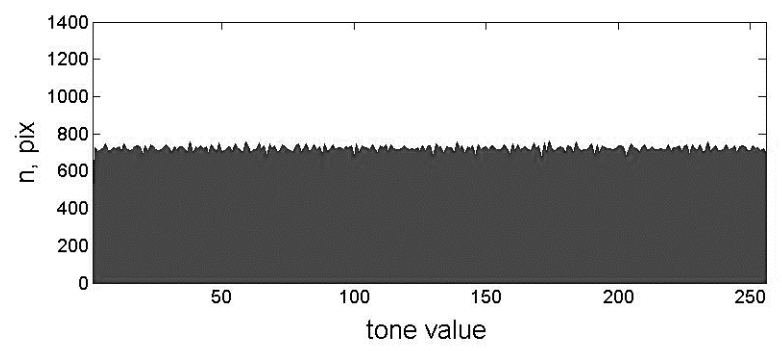

b)

Figure 1: The test image $-a$; The test image histogram $-b$

The test image is printed in the defined conditions. The press sheet is scanned with the test image to receive its histogram from the digital imprint image. There is only one requirement for scanner: linear tone transmission. Then it is required to reduce noises, formed because of screening structure of the image, to form the histogram. Gaussian blur filter is used with parameters calculated, based on resolution of digital imprint image and MTF of an eye. It allows to consider the visual perception of images. Methods of choosing filter parameters are described in the article (Гнибеда \& Андреев, 2016). After blur, the image histogram is received, then cumulative sum is counted (1), after that transformation function $T(I)$ and pre-correction functions (2) are counted. This pre-correction function will be applied to the test image, prepared for printing (Figure 2). 

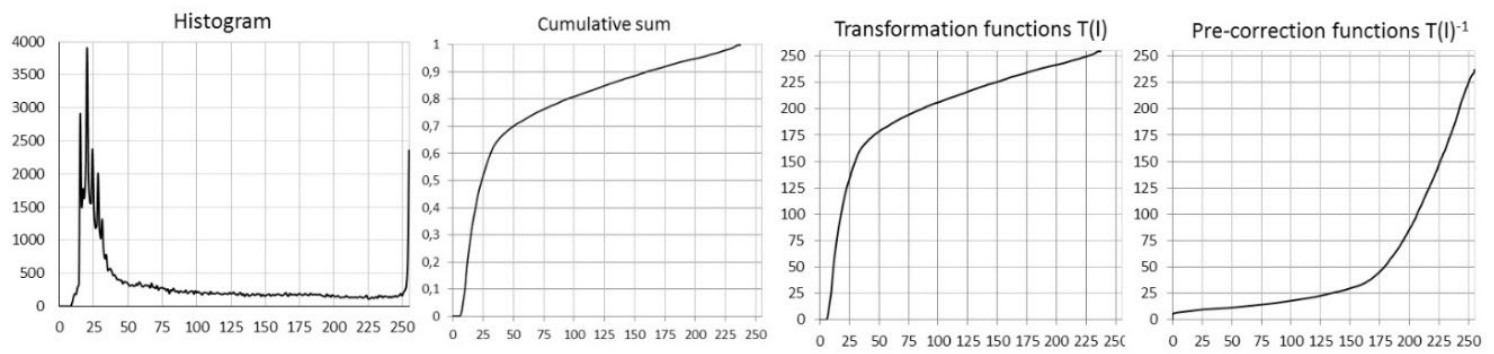

Figure 2: Receiving of pre-correction function

After that, the image is reprinted to receive digital imprint image histogram, which would be compared with the histogram of the original image.

Histograms can be compared both quantitatively and qualitatively. It is suggested to use histogram statistics for quantitative evaluation (Gonzalez and Woods, 2018).

The mean - $m$ shows an average value of lightness level in the image and allows to evaluate shifting of levels in light or dark zones of tonal range (3).

$m=\sum_{l=0}^{k} l P(l)$

The standard deviation $-\sigma$ allows to evaluate shifting of lightness levels in comparison with the mean (4).

$\sigma=\sqrt{\sum_{l=0}^{k}(l-m) P(l)}$

The Skewness - Skew shows asymmetry of histogram relative to the average value. If the value of Skew is negative, it means that histogram is shifted into the dark area, if Skew is positive, histogram is shifted into the light area (5).

Skew $=\frac{m-m e d}{\sigma}$,

where med - means median.

Comparing of these parameters, received from the original image and the digital imprint image, allows to evaluate distortions in tone transmission. Then closer would be these parameters, than more similar would be images in the tone transmitting.

\section{RESULTS}

The test image is screened with lineature $150 \mathrm{lpi}$ and printed on the electrographic printing machine Canon ImagePress C60 with standard profiles for different types of paper: glossy (gl), matte (mat) and without covering (off).

Digital imprint images are received by scanning with subsequent blur using the Gaussian filter.

It is possible to evaluate redistribution of lightness levels after screening and printing on received histograms (Пухова et al, 2018).

Pre-correction functions are counted for every type of paper (3), based on cumulative sums from histograms. They are applied to the base test image and as a result there are 3 images, prepared for printing on different types of paper. After all images are printed on the corresponding types of paper in the same condition as the test image.

After printing digital imprinting image histograms on different papers with applied Gaussian blur filter are received. These histograms are compared with the histogram of the original digital image and histograms of images without pre-correction (Figure 3), (Table 1).

It is visible, from shown histograms and statistic parameters, that press sheets with pre-correction are closer to the original image in the distribution of tones inside the tonal range. The algorithm of appliance of histogram methods for compensation of distributions of the printing process on the preprinting stage is developed, based on these results (Figure 4). 
gl

a

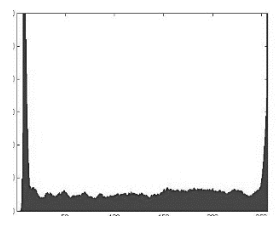

b

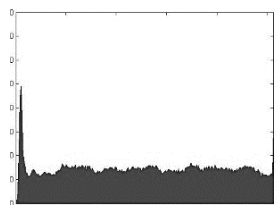

mat
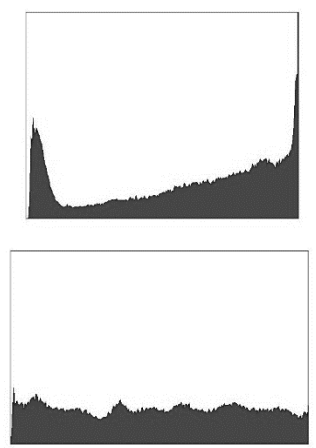

off

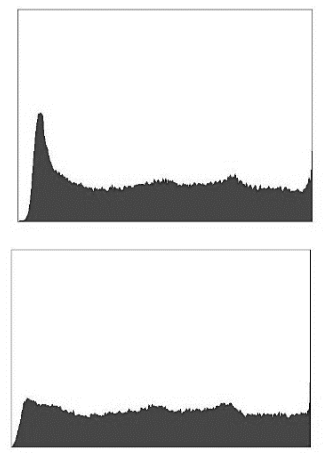

Figure 3: Histograms of digital imprint images on different types of paper $a$-without pre-correction; $b$ - with pre-correction

Table 1: Histogram statistics

\begin{tabular}{|l|c|c|c|}
\hline \multirow{2}{*}{ original } & m & $\sigma$ & Skew \\
\cline { 2 - 4 } & 128,00 & 73,76 & 0,00 \\
\hline gl & \multicolumn{5}{|l|}{} \\
\hline without pre-correction & 126,46 & 88,45 & $-0,06$ \\
\hline with pre-correction & 127,71 & 74,34 & $-0,01$ \\
\hline mat & 156,18 & 83,03 & $-0,26$ \\
\hline without pre-correction & 125,60 & 74,07 & $-0,02$ \\
\hline with pre-correction & \multicolumn{5}{|c|}{} \\
\hline off & 159,75 & 81,37 & $-0,26$ \\
\hline without pre-correction & 122,31 & 74,26 & 0,00 \\
\hline with pre-correction &
\end{tabular}

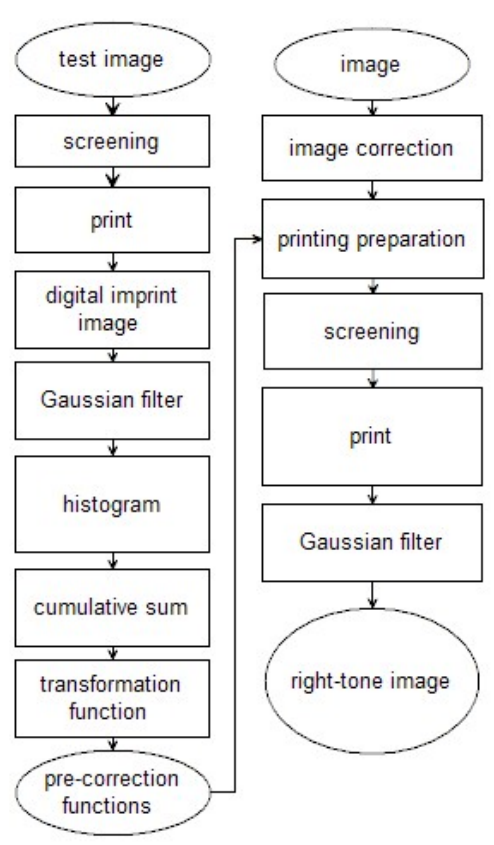

Figure 4: The algorithm of appliance of histogram methods for compensation of distributions of the printing process on the preprinting stage 
Let's see the realization of this algorithm on complex images. Pre-correction functions are applied to images before printing.

On Figure 5 there are images and their histograms, in Table 2 there are statistic parameters of histograms.

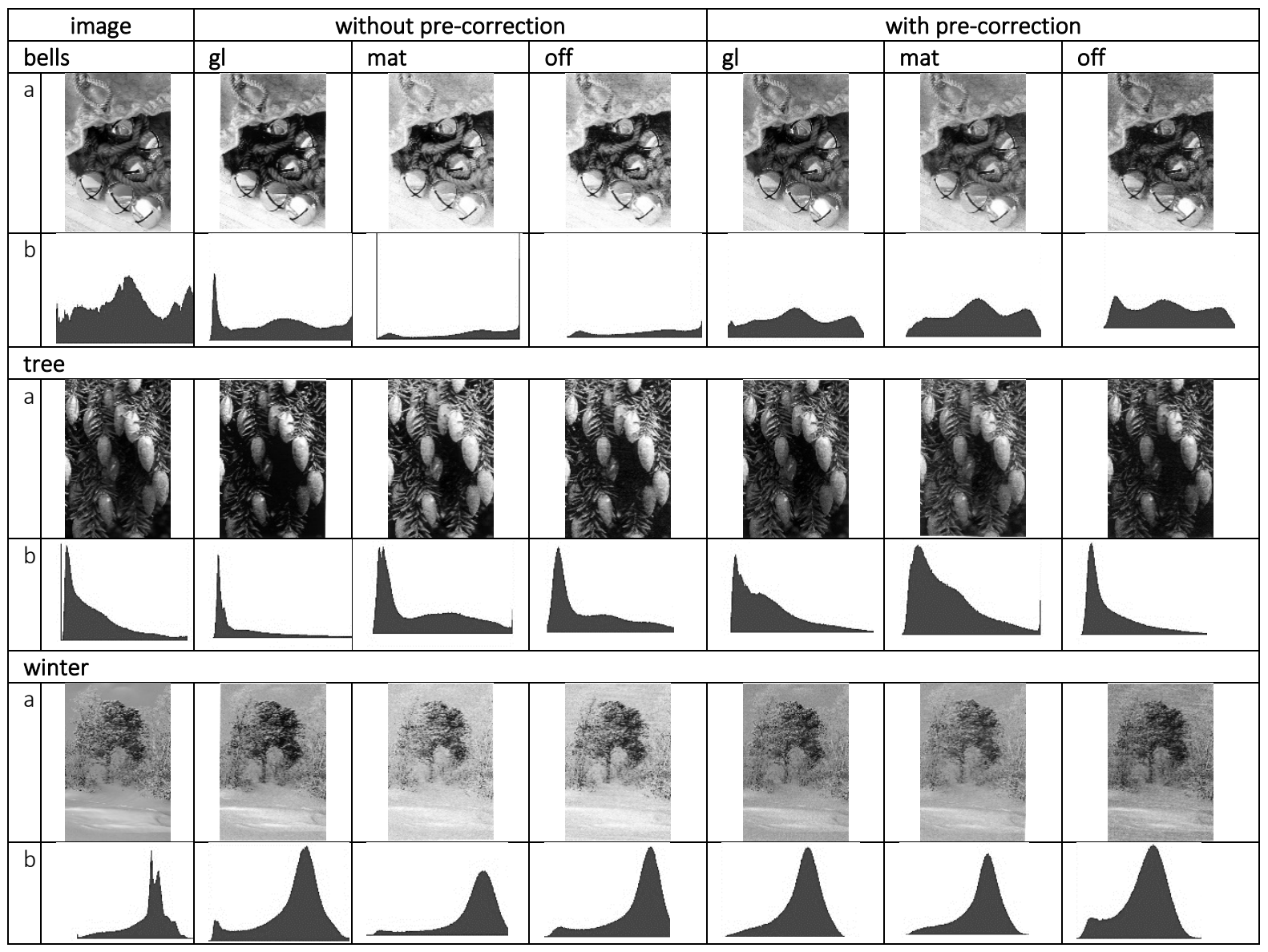

Figure 5: Images and histograms of digital images and digital imprinted images on different types of paper. $a$-image; $b$-histogram

Table 2 - Statistic parameters of histograms of digital images and digital imprinted images on different types of paper.

\begin{tabular}{|l|c|c|c|c|c|c|c|c|c|c|}
\hline \multicolumn{1}{|c|}{ bells } & \multicolumn{3}{c|}{ tree } & \multicolumn{3}{c|}{ winter } \\
\hline \multirow{2}{*}{ original } & $\mathbf{m}$ & $\boldsymbol{\sigma}$ & Skew & $\mathrm{m}$ & $\boldsymbol{\sigma}$ & Skew & $\mathrm{m}$ & $\boldsymbol{\sigma}$ & Skew \\
\cline { 2 - 10 } & 128,73 & 66,74 & 0,04 & 68,52 & 56,59 & 0,29 & 143,84 & 40,86 & $-0,22$ \\
\hline \multicolumn{8}{|c|}{ gl } \\
\hline without pre-correction & 134,78 & 81,02 & $-0,02$ & 60,53 & 64,57 & 0,49 & 152,12 & 50,81 & $-0,27$ \\
\hline with pre-correction & 128,69 & 66,45 & 0,04 & 67,94 & 56,05 & 0,25 & 142,87 & 39,99 & $-0,20$ \\
\hline \multicolumn{7}{|c|}{ mat } \\
\hline without pre-correction & 166,73 & 73,07 & $-0,24$ & 90,76 & 71,52 & 0,22 & 188,55 & 44,87 & $-0,28$ \\
\hline with pre-correction & 139,04 & 62,41 & 0,00 & 83,73 & 57,70 & 0,26 & 153,65 & 38,19 & $-0,22$ \\
\hline \multicolumn{8}{|c|}{ off } \\
\hline without pre-correction & 162,39 & 75,46 & $-0,19$ & 83,01 & 68,12 & 0,40 & 183,73 & 51,81 & $-0,35$ \\
\hline with pre-correction & 123,14 & 67,72 & 0,05 & 61,25 & 52,51 & 0,39 & 134,07 & 44,31 & $-0,20$ \\
\hline
\end{tabular}


Received data, calculated with histogram method, gives good results, for images with different tone distribution in tonal range and correction. Press sheets with pre-correction on different types of paper have tonal distribution, that is close to the original image.

\section{CONCLUSIONS}

A method of image preparation for printing reproduction is suggested. This method allows to automatically compensate transformations that occur during reproduction, by analyzing a histogram of test chart image and based on it, creating a compensation pre-correction function. It also takes into consideration the visual perception of images. Appliance of the described method does not require expensive hardware and software. Only scanner and programming module, with the described algorithm are needed. At this moment, algorithm is realized on Python. The suggested method allows to automatize the process of the image preparation for reproduction. It is an addition for another histogram correction methods.

This method can be spread on the colored images. To do so, it is required to analyze histograms of colored image channels and apply compensation to the corresponding channel.

\section{REFERENCES}

[1] Gonzalez, R. C.; Woods, R. E.: "Digital Image Processing", 4th edition, (Piarson: New York, 2018), page 1168.

[2] Гнибеда, А.Ю.; Андреев, Ю.С.: “Разработка метода оценки визуального восприятия однородности печатного изображения", Известия высших учебных заведений. Проблемы полиграфии и издательского дела, 1 (4), 63-70, 2016.

[3] Hunt, R.W.G.: "The Reproduction of Color", 2nd edition, (John Wiley \& Sons: Chichester, 2004), page 724.

[4] Маргулис, Д.: "Photoshop для профессионалов: классическое руководство по цветокоррекции", (пер. с англ. М.: ООО «Интерсофтмаррк», 2003), page 464.

[5] Нюберг, Н.Д.: “Теоретические основы цветной репродукции”, (Советская наука, 1947), page 177.

[6] Пухова, Е.А.; Андреев, Ю.С.; Винокур, А.И.: “Анализ и сопоставление методов градационной коррекции изображений, предназначенных для полиграфического воспроизведения", Известия высших учебных заведений. Проблемы полиграфии и издательского дела 2016, 1 (3), 28-34.

[7] Пухова, Е.А.; Андреев, Ю.С.; Панкин, О.В.: “Оценка гистограммных преобразований в печатном процессе", Известия Тульского государственного университета. Технические науки 1 (6), 298-308, 2018.

[8] Пухова, Е.А.; Андреев, Ю.С.: “Коррекция цвета изображений методом приведения гистограммы по закону нормального распределения", Известия ТулГУ серия технические науки 6, 335-347, 2017.

[9] Пухова, Е.А.; Андреев, Ю.С.: “Применение гистограммной коррекции для устранения градационных искажений при цифровой обработке изображений”, Известия высших учебных заведений. Проблемы полиграфии и издательского дела 1 (6), 41-47, 2014.

[10] Пухова Е.А., Андреев Ю.С.: “Применение гистограммных методов для коррекции черно-белых и цветных изображений”, (Материалы научно-практической конференции Innovations of publishing, printing and multimedia technologies' Kaunas, 2018), pages 113-121.

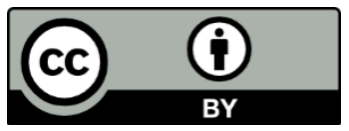

(C) 2020 Authors. Published by the University of Novi Sad, Faculty of Technical Sciences, Department of Graphic Engineering and Design. This article is an open access article distributed under the terms and conditions of the Creative Commons Attribution license 3.0 Serbia (http://creativecommons.org/licenses/by/3.0/rs/). 